\title{
Paradigms of Sex Research and Women in STEM
}

\author{
Jeffrey W. Lockhart \\ University of Michigan \\ Department of Sociology and Center for the Study of Complex Systems \\ jwlock@umich.edu \\ 4. August 2022 \\ Preprint - Accepted Manuscript
}

Suggested citation:

Lockhart, Jeffrey W. 2021. "Paradigms of Sex Research and Women in STEM." Gender \& Society 35(3): 449-475.

SocArXiv preprint: https://osf.io/preprints/socarxiv/zajyg

Supplemental materials and data: $\underline{\text { https://osf.io/4jmuw }}$

Publisher's version: https://journals.sagepub.com/eprint/JMFNA939HPATJVF37SRI/full 
Lockhart $\mid 2$

\begin{abstract}
Scientists' identities and social locations influence their work, but the content of scientific work can also influence scientists. Theory from feminist science studies, autoethnographic accounts, interviews, and experiments indicate that the substance of scientific research can have profound effects on how scientists are treated by colleagues and their sense of belonging in science. I bring together this disparate literature under the framework of professional cultures and show population-level trends supporting it. Drawing on the Survey of Earned Doctorates and the Web of Science, I use computational social science tools to argue that the way scientists write about sex in their research influences the future gender ratio of PhDs awarded across 53 subfields of the life sciences over a span of 47 years. Specifically, I show that a critical paradigm of "feminist biology" that seeks to de-essentialize sex and gender corresponds to increases in women's graduation rates, while "sex difference" research—sometimes called "neurosexism" because of its emphasis on essential, categorical differences-has negative effects on women's graduation rates in most fields.
\end{abstract}


Paradigms of Sex Research and Women in STEM | 3

In 2005 Harvard University's president, Lawrence Summers, sparked heated debates over the causes of women's under-representation in many STEM fields. He claimed scientific research led him to believe that "intrinsic aptitude" was more important than "socialization and continuing discrimination" (2005). That is, women are less likely to be biologically capable of STEM work. While Summers' remarks were a flash point of widespread public attention, the views that they reflect are a longstanding fixture in scientific research on sex. The tradition of sex difference research stretches much further back than Summers' suggested date of 1990, and it continues to guide publications and inflame scientific debates today, with over 1,100 academic publications on sex difference in 2017 alone (Sanz 2017; Lockhart 2020). Scientific claims of women's inferiority are not new. Nor, sadly, are they old.

It is axiomatic among sociologists of science that the content of scientific work is not independent from the social lives of scientists. Typically arguments focus on how scientists' social positions influence their work. I explore evidence for influences in the opposite direction. The content of scientific research may influence who becomes a scientist, because the content of scientific work is a part of the professional culture of scientific fields. Characteristics of "good science" like dispassionate objectivity get transposed into characteristics of "good scientists," often in ways that discredit women and other people with marginalized identities (Cech 2013a; Haraway 1988; Subramaniam 2000). The content of science can both reflect and influence the "schemas of inequality" within a field, which in turn affect selection, persistence, evaluation, promotion, resources, equity initiatives, and more (Cech 2013b). This process may be especially clear in research on the biological dimensions of sex, where scientists openly debate the abilities, 
preferences, and ultimate merits of men and women in both the content of their research and their professional career interactions.

To be sure, there is an extensive literature on women's (under)representation in science and in occupations more generally. A google scholar search for "women in science" returns 4.5 million results. As Nancy Brickhouse notes, this research has "provided us with ideas about what could be done to change the domination of men in science and science education. However, this research did not address epistemology and thus left unquestioned traditional conceptions of what counts as knowledge" (2001, 282-83). Next to findings about culture, discrimination, educational tracking, ideal worker norms, and more, the contents of published sex research are not the only or the largest influences on women's participation in science. Nevertheless I use large-scale quantitative analysis to argue, along with other feminist scientists and feminist science studies scholars, that the way scientists write about sex matters (Hubbard 1990; Martin 1991; Sanz 2017).

Specifically, I propose and test a link between the content of scientific research on sex and women's subsequent representation in 53 subfields of the life sciences over the course of 47 years. I draw on newly available historical data from the National Science Foundation's Survey of Earned Doctorates (SED) on the prevalence of women in detailed academic subfields from 1970 to 2017. I match this data with the Web of Science Core Collection (WoS) database, containing 69 million academic publications. I show that the amount of publications positing innate, categorical differences between men and women in biological and health science subfields is negatively related to the proportion of women earning PhDs in the same subfield in future years. To my surprise, however, I find the opposite effect in psychology subfields. 
Paradigms of Sex Research and Women in STEM $\mid 5$

Furthermore, I show that alternate paradigms of sex research in the same life science fields have different effects. Critical feminist research that challenges biological essentialism is associated with future increases in women's graduation rates, but research narrowly aimed at including women to improve their health outcomes has no effect. Perhaps more STEM research should take a critical feminist approach.

\section{PARADIGMS OF SEX RESEARCH IN THE LIFE SCIENCES}

In order to understand the effects of how life scientists write about sex, it helps to know what they say. Today, there are three main paradigms for making sex the object of study: Sex Differences, Feminist Biology, and Gender Medicine.

Sex differences research approaches sex categorically, as male or female, and seeks biological explanations for observed differences between them. Much of this research has focused on cognitive abilities and behaviors, leading to questions like whether "female brains" are capable of or interested in STEM employment. Although the biological specifics of sex difference research have changed considerably over time, this core approach-essentializing differences between categories - has been relatively stable (Sanz 2017; Lockhart 2020). Critics label some of this work "neurosexism" (Fine 2013; Bluhm 2021). If research is sexist, it may disproportionately attract and retain men. Not all women scientists see this paradigm as sexist, however. A number of women have made careers on conducting sex difference research.

This research has a large cultural presence outside academia. It showed up in news coverage of Summers' 2005 remarks and in James Damore's 2017 "Google memo" against hiring women engineers. Steven Pinker and Charles Murray are vocal proponents of the paradigm in popular media and venues like the American Enterprise Institute. Sex difference 
research is a perennial subject of boundary work in professional sports, determining who can compete in women's events and leagues (Pielke and Pape 2019; Davis 2015; Karkazis and Jordan-Young 2015). It has become especially popular recently with "trans exclusionary radical feminists," who cite biological sex differences as justifications to deny trans people's demands for civil and medical rights. Such scientists form organizations, give invited talks, and serve as expert witnesses (e.g. Hilton and Whyte 2020; World Rugby 2020).

Social scientists have critiqued the sex difference paradigm repeatedly for misunderstanding the social dimensions of gender differences (Quadagno 1979; Tuana 1983; Richardson et al. 2020). The causal direction of biological-social correlations is not obvious: observed physiological and cognitive differences are sometimes caused by social factors, such as the stress of being a token in the workplace or practiced repetition of gendered activities (Taylor 2016; Fausto-Sterling 2005). In 2000, when J. Richard Udry advocated the sex difference paradigm in American Sociological Review, Barbara Risman's reply noted that his article was published "without citing or directly engaging the concepts, arguments, and findings of the considerable literature on the sociology of gender that has been developed over the past 30 years" $(2001,606)$. This is true of the sex difference literature in general: it makes social claims without engaging the social science literature (Lockhart 2020).

There has long been feminist resistance to the sex difference paradigm (e.g. Poulain de La Barre 1677; Lowie and Hollingworth 1916; Herschberger 1948). In the 1970s, buoyed by their local feminist communities, newfound academic job security, and the success of a burgeoning community of feminist primatologists, a group of women in biology began to coalesce around a new paradigm of sex research: feminist biology (Hubbard 1990). These 
Paradigms of Sex Research and Women in STEM $\mid 7$ scholars sought to build "two way streets" between feminism and biology, arguing that biological research on sex is improved scientifically and culturally by replacing essentialist dichotomies with increased complexity (Hubbard et al. 1993; Fausto-Sterling 1992). They typically argue that differences between two categories are a poor description of the underlying biology. Many aspects of sex (such as hormone levels) are better measured as continuous variables with complex interactions and social/environmental influences. Concepts like "female brains" are misguided holdovers from a sexist past. They also tend to critique it on ethical grounds, arguing that seeking to prove superiority or justify patterns of inequality is not a good use of our energy compared with alleviating human suffering and expanding opportunities for everyone (for this argument in sociology, see Meadow 2013). Feminist biologists made big contributions to feminist standpoint theory and to critiques of rationality (for review, see Sanz 2017). They have institutionalized over time, with edited volumes, readers, mailing lists, conferences, and labs.

In the 1990s, a third paradigm of sex research rose under the banner of "gender-specific medicine" and "gender biology" (Epstein 2007; Roy 2012). This work calls for greater inclusion of women as subjects in medical research, arguing that treatment and diagnosis of women risked unforeseen harms if medical research remained focused on men. Some of the early research findings that popularized this paradigm, such as prescribing different dosage of sleep medication for men and women, have not stood up well over time (Richardson et al. 2015). Nevertheless, it has been institutionalized with great success. There is a journal and professional society for "gender medicine," and the NIH now requires the inclusion of "sex as a biological variable" in all their funded research. Gender medicine reflects aspects of both sex difference and feminist 
biology paradigms. It proceeds from an assumption of essential, categorical sex differences, but it explicitly aims to help women and to correct problematic assumptions about sex in research.

Debates among these paradigms are ongoing, with scientists writing both scientific articles and popular media advancing their chosen paradigm. No Kuhnian revolution has taken place. Instead, these paradigms behave more like Panofsky's "misbehaving science," reiterating old arguments in insular communities without resolving conflicts (Panofsky 2014; Sanz 2017; Lockhart 2020). But the conversation is not entirely stagnant. The biological details that serve as battlegrounds for these debates have shifted over time among subfields like endocrinology, neuroscience, and genetics. This provides the variation for my analysis.

\section{PROFESSIONAL CULTURES AND THE CONTENT OF SCIENCE}

Professional culture is the semi-autonomous system of meanings, symbols, and habits associated with a profession (Abbott 1988; Cech 2013b). Research on professional cultures has demonstrated that STEM fields draw on varying "schemas of inequality" and "merit" that shape the experiences and career trajectories of scientists (Cech 2013b; Cech, Blair-Loy, and Rogers 2018). These schemas are inculcated during graduate education, and they disproportionately impact the success of students in raced, classed, and gendered ways (Cech 2014; Costello 2005). Gendered schemas about "natural differences" between men and women affect who is valued in the workplace (Schilt 2010), and increasing the number of women in an occupation does not necessarily change them (Hochschild and Machung 1989). The schemas by which scientists judge one anther's abilities, preferences, and merit (Lamont 2009), might reasonably be expected to manifest in and be informed by those same scientists' publications about human abilities, preferences, and merits. Typically, professional cultures and schemas of inequality are studied in 
Paradigms of Sex Research and Women in STEM $\mid 9$ rich detail with interviews and ethnography, or across broader segments of the STEM workforce with cross sectional surveys. By using the content of publications and an annual census of doctoral recipients, I provide a population level view of the same processes over half a century. There is much research on local processes by which research publications may influence professional cultures and thus overall trends in the gender balance of scientific fields.

From their beginnings in the late 1960s and early 1970s, women's studies, women's health, women's biology_as well as African American studies-were expressly intended, among other things, to attract and retain more women and Black people in academia by changing the content of curricula and research (Messer-Davidow 2002; Johnson 2020). Others have made the same arguments in physics and chemistry: rethinking curriculum and research through a feminist lens not only improves their content, but should attract and retain more diverse science practitioners (Barad 1995; Barton 1997). Simultaneously, proponents of sex difference research have openly resisted calls to bring more women into STEM on the grounds that disparities reflect natural differences rather than social problems (Hubbard 1990). These paradigm fights have always been partly about influencing the demographics of scientists, not only the "objective truth" of biology and sex.

The content of research can exert push and pull effects on individuals. For instance men — even those few who select into women's studies courses - tend to distance ourselves from things labeled "feminism" (McCabe 2005; Pleasants 2011). "Feminist science," then, may both attract women and repel men. At the same time, science that questions women's inherent ability or pushes essentialist views of sex may create a hostile environment that pushes women, 
intersex, nonbinary, and trans students out (Philosopher 2019). Working in a hostile discipline can take its toll. As Tey Meadow powerfully put it, the very publication of studies like the NFSS exacts a particular form of psychic violence - on families, on families like mine, on scholars like me. As a sociologist and a gay parent, I can withstand the accusations of instability and unfitness it levies.... I can sit in rooms at professional conferences and watch my peers and colleagues dispassionately debate the legitimacy of my relationship and the fundamental right of my family to exist.... The question is whether I should have to (2013).

Such research contributes to a field's professional culture, conveying two messages to students and faculty mentors. First, one's ability or worth is a function of their identity. Second, one's comparative merit and innate character are acceptable — even rewarded—lines of inquiry in their field. Such publications advance a particular schema of inequality by naturalizing group inferiority.

Likewise, devaluing critical feminist research can have detrimental effects on students. Carla Pfeffer (2018) describes the experience of being denied a dissertation grant because reviewers did not believe she could "build a career" or get publications in "the most prestigious" journals by studying the cis women partners of trans men. Negative "feedback may carry a particularly shaming valence for queer scholars if they are told, essentially, that projects reflecting their lives carry little broader import or value," and this can make them doubt their "future career prospects altogether" (Pfeffer 2018, 310). Research on sex differences does not debate women's right to exist, and in that sense is not the same kind of psychic violence often 
directed at LGB and especially trans people, and also at people of color, people with disabilities, and other groups' whose merit is routinely debated by scientists. But sex research does nevertheless debate women's fitness and place in the world. In these cases, developing a professional identity consonant with one's field may require extensive and potentially ruinous emotional labor and loss of identity (Subramaniam 2000). Professional identities dissonant with professional cultures lead to decreased success in graduate school for women and underrepresented groups (Costello 2005).

Moreover, people are prone to believing sex research claims. Summers' comments demonstrate that reading essentialist research about sex can lead people to believe that women are less capable of STEM work. Importantly, bio-essentialist research does not need to speak directly to men and women's relative STEM ability to influence beliefs about it. In the question period after his 2005 remarks, Summers' was asked for evidence to support his claims about women's inability to do STEM work. He replied,

the field of behavioral genetics had a revolution... the discovery that a large number of things that people thought were due to socialization weren't, and were in fact due to more intrinsic human nature, and that set of discoveries, it seemed to me, ought to influence the way one thought about other areas (2005).

Summers had no relevant research to cite. Instead, he pivoted to generic research in a move that Donovan et al. (2019) call "neurogenic essentialism." They find scientific research can have this effect on audiences "by activating and strengthening any or all of the following four beliefs composing neurogenetic essentialism: The uniformity of categories [like man and woman], the discreteness of categories, the underlying essence of categories, and the causal influence of this 
essence on category members" $(2019,722)$. An array of experiments has shown that reading essentialist explanations of sex differences in newspapers or science textbooks increases prejudiced beliefs about women as a whole, as well as stereotype threat and fear of discrimination among women and girls. These effects hold even when the research presented is not about the stereotype measured (e.g. women and STEM) (Brescoll and LaFrance 2004; Ching and Xu 2018; Coleman and Hong 2008; Donovan et al. 2019).

With regard to professional culture, prejudiced beliefs about gender may influence how men and women are evaluated and the overall climate women experience in science or graduate school. Research on the field-specific ability beliefs (FAB) hypothesis finds that the proportion of women in academic fields corresponds with how much practitioners in those fields say success "requires a special aptitude that just can’t be taught" (Leslie et al. 2015). The mechanism for this association remains elusive (Bailey et al. 2019), perhaps in part because this work assumes there is a uniformly negative cultural association between "woman" and "genius." Such a relationship has been demonstrated in many relevant cases (Ridgeway 2011; Musto 2019; Storage et al. 2016). However, my analysis of publications shows that beliefs about the relationship between gender and innate ability are not uniform across academic fields or over time. This variation in gender stereotypes predicts women's representation in the life sciences, making it a missing piece in $\mathrm{FAB}$ research.

Essentialist gender beliefs may also interact with ideal worker norms that set long hours and high job dedication as expectations for STEM work, contrasting those qualities with bioessentialist notions of women's family preferences. Ideal worker norms have tangible implications for women in STEM, for example by disproportionately tracking them out of 
research when they have children (Cech and Blair-Loy 2019). Such research may also make scientific ideal worker norms harder for women to achieve in other ways. In fields where a social group's "nature" is a valid object of study, members of that group may be viewed pejoratively as "mesearchers" incapable of objectivity (Haraway 1988; Pfeffer 2018). Or due to the stress and insult of such work, they may have difficulty maintaining the detached collegiality necessary for career advancement (Cech 2013b; Subramaniam 2000).

These findings also point to structural concerns. Sex difference research can influence university presidents like Summers to believe that they should not allocate resources to gender equity initiatives. Essentialist beliefs about sex enable practitioners to continue believing that science is a functional meritocracy, even when presented with substantial gender disparities; these beliefs are a major barrier to gender equality in STEM (Cech 2017; Hubbard 1990; Seron et al. 2018). By affecting fields, this research affects a student's experience whether or not they personally read papers about sex. Further, students match with mentors and departments on the topics they study. This process implicates students' social identities: LGBTQ undergraduates use the topics fields study to understand whether those fields are "queer-free" or "queer-friendly," and thus whether they belong (Forbes 2020). $\mathrm{PhD}$ funding in the life sciences is dependent on how valued a student's topic is (Belavy, Owen, and Livingston 2020). Mentor prestige and financial resources are key factors in life science $\mathrm{PhD}$ success and retention, outweighing prior academic achievement (Belavy, Owen, and Livingston 2020). Thus the success and prestige of sex research paradigms (signaled to academics through publications) may influence graduate students' choice of subfield and persistence by shaping the resources available to them and their mentors. Indeed, some gaps in funding, training environment, and career outcomes between men 
and women STEM $\mathrm{PhD}$ students can be accounted for by variation dissertation topics (Buffington et al. 2016).

Of course, the relationship between publication content and professional cultures is not one directional. As Prescod-Weinstein explains, even if the paradigm she names "white empiricism" is rare in physics,

What matters is that their arguments are given room to breathe in professional spaces, whether it is publications, conferences, or books.... While many in the community may disagree..., their epistemic agency is recognized as legitimate. Black women speaking up about their experiences with discrimination are simply not offered the same platforms or axiomatic acceptance of their agency in discourses about race and gender/sex" $(2020,430)$.

The culture of a field affects what is published and who is listened to. Aaron Panofsky explains that behavior genetics persists without addressing criticism, because practitioners exist in fields that value their work, while their critics are only influential in other fields to which they are unaccountable (2014). Thus field-specific professional cultures influence the content of published research, and within-field publications are the primary research influence on scientists.

Taken together, the various mechanisms outlined in this section suggest that the kinds of sex research being published shapes the professional cultures of scientific fields in ways that likely influence the gender ratio of $\mathrm{PhD}$ recipients. Sex difference research may decrease the relative numbers of women entering a field, while explicitly feminist approaches may increase it. 


\section{DATA}

\section{Sources}

The NSF Survey of Earned Doctorates (SED) is an annual census of research doctorate recipients in the United States (in 1970, N=28,861. In 2017, N=54,664). It collects self-report surveys and supplements missing information with school records. SED staff created a new public tabulation of the microdata for me which includes counts of doctorates granted by year (1970-2017), detailed subfield of study, and sex ([male, female]). Field classifications are standardized across years. Missing data is less than $1 \%$ in all years, and 0 in most years. Small cells are suppressed: in field-years where the number of men or women finishing a $\mathrm{PhD}$ is between 1 and 4, inclusive, the exact number and sex ratio are hidden. Example data is shown in Figure 1. 
I restrict my sample to the SED categories "Biological and Biomedical Sciences," "Health Sciences," "Psychology," and "Anthropology," as these are the fields where paradigm battles between sex differences, feminist biology, and gender medicine have primarily taken place. I exclude administrative subfields such as "Health Systems Administration" and those with fewer than 10 years of data. I combine general, cultural, and physical anthropology, which were not measured separately until 2014. I do the same for psychometrics and quantitative psychology. The resulting subfields include some core battlegrounds of sex research (e.g. endocrinology, biological psychology, developmental biology) as well as more removed areas (e.g. microbiology, plant science). They represent the universe of available PhD fields for students interested in the life sciences. The SED data has gender ratio for 1,956 field-years, out of a possible 2,491 (53 fields observed on average 36.9 of 47 possible years).

While most of these fields see increases in women's representation, the rate and timing of growth varies dramatically. Some fields, such as genetics and nursing, see very little change over time. Some start near gender parity, while others start with dramatic inequality. Some subfields achieve or exceed parity, while others never attain it. This paper takes a comparative approach. It is not set up to explain changes in the overall number of women in science or the historical circumstances that have contributed to that. Instead, I compare life science subfields in order to see whether the content of research in those subfields can explain some of why the trajectories of women's participation look so different from one subfield to the next.

The Web of Science Core Collection (WoS) is a database of academic publications, metadata, and citations. It has 69 million documents cataloged between 1900 and 2018. I use a copy of the entire raw WoS database, rather than search results from the online WoS interface. 

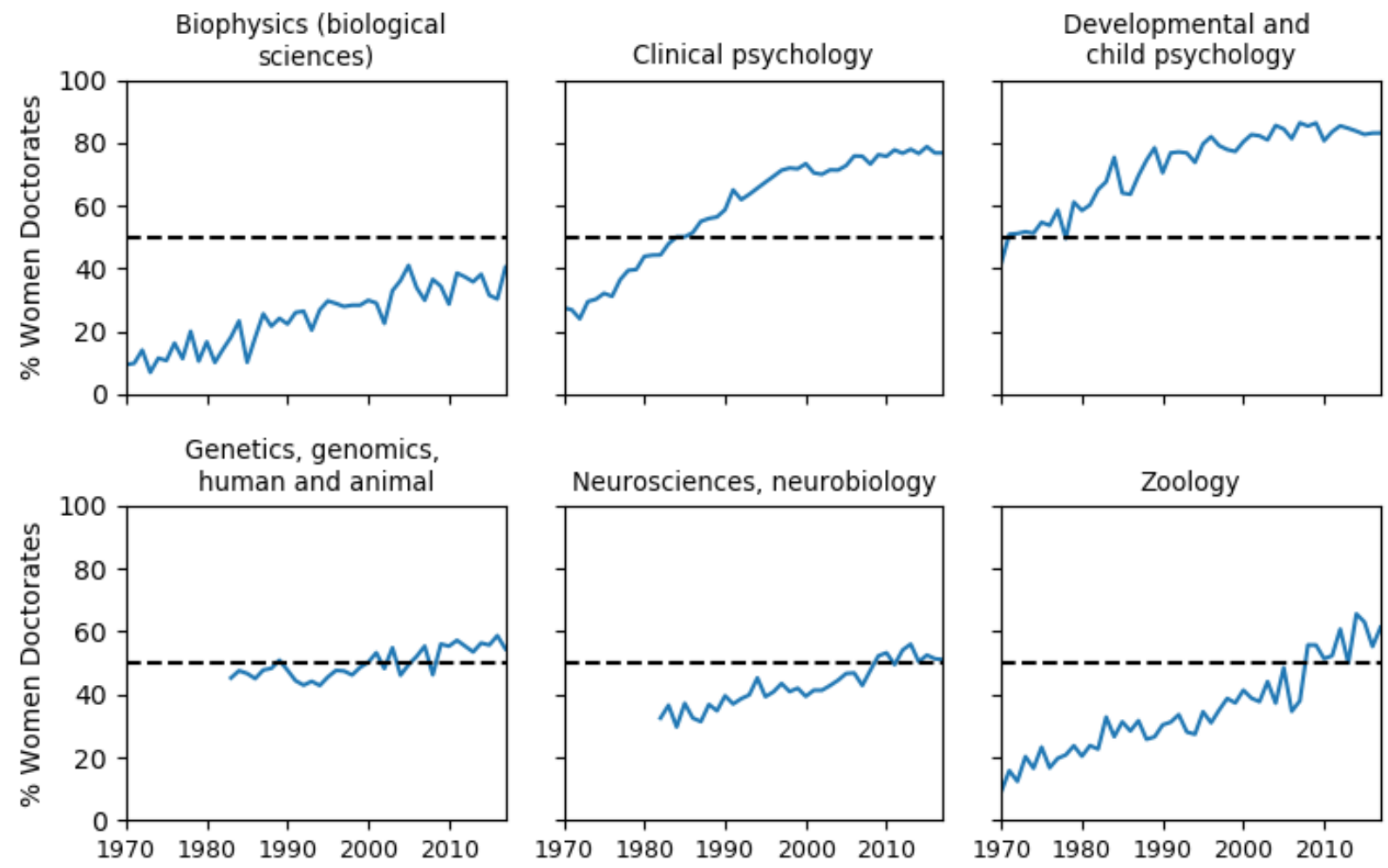

Figure 1: Percent women earning doctorates in select subfields over time.

This presents a more comprehensive view of research subfields than sampling a handful of top journals, but the WoS database is still biased toward more established and higher ranked journals over books and newer or more obscure journals. I further restrict it to English publications. A substantial amount of feminist science has been published in the journals Hypatia, which is not indexed by WoS, and Signs, which is indexed under the humanities and not under science subjects. These omissions would limit inferences about feminist science as a whole but not my analysis of within-field effects. Prior work has shown that scientists are held accountable to within-field publications rather than cross-field critiques (Panofsky 2014). Because the database was shared as 735 GB of unwieldy XML files, I used python and spark on one of my university's high performance computing clusters to conduct analysis. 
Lockhart $\mid 18$

\section{Linking}

The SED and WoS use different taxonomies for research fields. I manually matched the SED fields to their WoS counterparts, consulting the documentation for both. Many were simple (e.g. "Clinical psychology" in SED corresponds to "Psychology, clinical" in WoS). Several subfields of psychology in the SED (namely: cognitive, community, comparative, counseling, family, organizational, personality, and social) were not distinguished in the WoS subject classifications. These I matched on keywords in book and journal titles, manually checking matches to ensure accuracy. In one case I was unable to obtain good matches, so instead I combined the SED categories for plant genetics, physiology, and pathology so that they correspond to the WoS category "plant science." The 53 life-science subfields of the SED matched with $38,541,924$ WoS publications.

\section{Paradigm Labels}

I designed a set of keyword matches and exclusions to label each publication in the matched WoS sample for which paradigms it invokes, if any. To design and test my labeling, I relied heavily on a parallel qualitative project where I study the rhetorical strategies deployed in sex research paradigm debates (Lockhart 2020). For this analysis, any publication with "feminism", "feminist", "sex similarit", or "gender similarit" in the title, abstract, or keywords was labeled as engaging the feminist biology paradigm, along with anything published in journals or books with "feminism" or "feminist" in the title. "Feminist" and "feminism" had to be specified separately to exclude references to "feminizing." The other terms were included to capture references to Janet Hyde's influential "Gender Similarities Hypothesis" (2005). Explicit references to feminism or gender similarities in scientific writing are hallmarks of the paradigm 
and they send strong signals of membership to readers. This resulted in 7,195 life science publications $(0.04 \%)$ being labeled "feminist biology."

Publications were labeled as engaging the sex difference paradigm if they used any of the following in their title, abstract, or keywords: "sex differen", "sexual dimorphism", "sexually dimorphic", or "[fe]male brain", or if they were in a book or journal with a title containing "sex differen". These terms are prolific in research under the sex difference paradigm. I did not include matches on "gender differences", because qualitatively reviewing the matches to that term indicated that most of them were focused entirely on social phenomena without reference to biological underpinnings, consistent with the use of "sex" and "gender" to distinguish between "nature" and "culture." This resulted in 42,901 life science publications $(0.25 \%)$ being labeled “sex differences."

Finally, publications were labeled as engaging the gender medicine paradigm if their title, abstract, or keywords matched any of these terms: "sex based", "gender based", "gender specific", "sex specific", or "gender medicine", or if they were published in a journal or book with a title containing "gender medicine", "gender specific", "sex specific", or "journal of womens health" but not "international". This search captures the core literature of this paradigm, as described by Epstein (2007). This resulted in 27,646 life science publications $(0.16 \%)$ labeled "gender medicine." While many of these terms seem general on face, in the context of life science publications, they correspond very closely with the gender medicine paradigm. For example, "sex based differences" is almost exclusively used in the context of clinical health and medicine research, while "sex differences" is the term of choice elsewhere. 
Over 12 months I checked and refined the labeling process to ensure that it included important works and excluded false positives such as "feminist science fiction," which matched initial searches for "feminist science." This period also included iteratively standardizing punctuation, spacing, and capitalization in the WoS database to improve text matching.

Importantly, I measure the paradigms represented, not the position of authors or substance of findings. Thus a paper that declares "no sex difference" in some trait is still labeled as a sex difference paper, because it uses the rhetoric of that paradigm and frames research on sex as a question of categorical difference. Similarly, a "feminist critique of sex difference" would be categorized as both feminist and sex difference, since it rhetorically engages both paradigms, regardless of where the author ultimately sides. Overlaps between categories were extremely rare: only $0.17 \%$ of feminist biology and sex difference articles overlapped. Overlap between feminist biology and gender medicine was $0.27 \%$, and overlap between sex differences and gender medicine was $6.0 \%$. This suggests that my classification schema achieves a good separation of the paradigms, despite potential ambiguity in the rhetorical landscape.

Categorizing work this way necessarily entails simplifying large and complicated literatures. However, these three paradigms are well documented in sex research, and after iteratively refining the labeling process, reviewing random samples of the results, and finding very little overlap between categories, I am confident that my approach aligns well with these paradigms of sex research.

While articles using any of these three paradigms are rare in the life sciences overall, their relative prevalence varies substantially across time and subfields. Figure 2 shows paradigm prevalence in four subfields. In microbiology, there has been little debate over sex research, 
Paradigms of Sex Research and Women in STEM | 21

which makes sense because the subjects of microbiology research include bacteria, fungi, and viruses. By contrast, all three paradigms have been more popular in general psychology, where feminist biology and sex difference publications were equally prevalent throughout the 1990s, but sex difference research was dominant in other periods. Developmental psychology was one of the early sites of debates around childhood gender, and as expected, it has a greater and earlier engagement with these paradigms. 

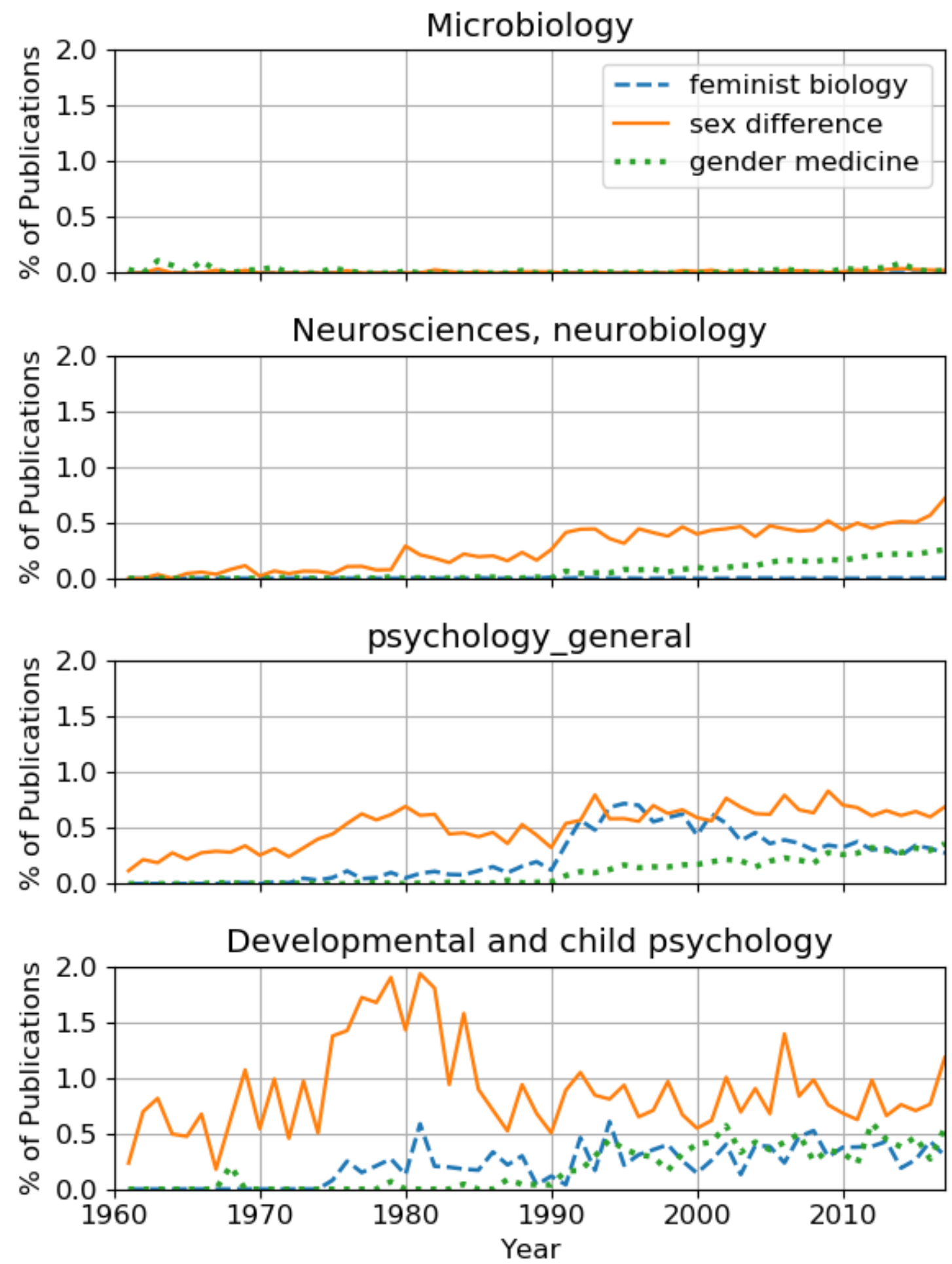

Figure 2: Prevalence of paradigms over time in select subfields 
Paradigms of Sex Research and Women in STEM | 23

\section{MODELING}

I use linear mixed effects growth models to study the relationship between paradigm prevalence and women's share of earned doctorates in life science subfields. By incorporating subfield-level random slopes and random intercepts, these models allow me to examine variation both within and between subfields in both the overall level and rate of increase in women's participation. Put differently, these models allow the regression lines (trajectories of women's participation) for each of the subfields in Figure 1 to vary, while still leveraging information from the full sample (partial pooling).

Dependent variable: Percent of doctoral recipients who are women, by subfield and year, from the SED. (Unfortunately, NSF surveys of enrolled graduate students use a different set of subfield categories than the SED, so it is not possible to disaggregate the effects of selection into doctoral programs from attrition on degree outcomes.)

Independent variables: for each of the three paradigms, I create a lagged prevalence variable. These variables correspond to the percentage of publications in a subfield, during the previous five years, that were labeled with a given paradigm. For example the variable feminist biology for microbiology in 2006 is the percent of microbiology papers published from 20012005, inclusive, that were labeled "feminist biology." This lag corresponds roughly to the time period when doctorate recipients would have been graduate students, because undergraduate ability beliefs have been shown not to track with $\mathrm{PhD}$ outcomes (Bailey et al. 2019). Since 1970, mean time-to-degree for life science doctorates in the SED has fluctuated between 6.2 and 7.7 years (Laurence 2014). 
Models: I construct three mixed effects growth models. The first follows Barr et al.'s (2013) advice to "keep it maximal" and include fixed and random effects for all terms. Thus Model 1 includes both fixed and random effects for subfield, time (years since 1970), and the lagged prevalence of feminist, sex difference, and gender medicine research, along with covariances for all combinations thereof. However, maximal models are often overparameterized: they may fit more terms than the data can support, fail to converge, and be difficult to interpret. Thus I also fit Model 2, with fixed and random effects for subfield and time, but only fixed effects for the three paradigms (Bates et al. 2018).

I repeat these analysis using a two-way fixed effects model, Model 3, with fixed effects for both subfield and year. Such models are much more conservative, as they remove time trends and between-field variation, leaving only within-field, time-independent effects. That is, they control away much of the variation I am interested in, because I expect that between-field differences in sex research paradigms will influence fields' trajectories over time. If this model shows effects for paradigm prevalence, it will be evidence of a local influence: the prevalence of sex research paradigms in a particular field and time influences the rate of women's graduation above and beyond broader field and time trends.

I use cross validation to test the robustness of my findings to sampling decisions. To do this, I create subsets of the data with each of the subfields omitted. I create additional subsets, with each of the broad fields omitted and with each broad field in isolation. I fit the same model specifications to all subsets of the data and evaluate whether the inclusion/exclusion of specific fields or subfields substantively changes the results. The cross-validation results suggest an interaction between the broad field of psychology and the prevalence of sex difference research, 
Paradigms of Sex Research and Women in STEM $\mid 25$

so I fit Model 4 with the same specification as Model 2, but with the interaction added as a fixed effect. (In Model 1, the random effects already capture this between-field variation in the effect of sex difference publications.)

Because not all publications are equally influential, I repeat all of these analyses weighting publications by their citations. A publication's weight is set to the number of papers citing it within five years of publication, plus one (the publication itself), logged due to the long tail. These models produce qualitatively similar results but are not shown because "log citation units" are harder to interpret than simple fractions of published articles.

\section{RESULTS}

Selected results for Models 1-4 are shown in Table 1. To my surprise, they show stronger and more robust effects for the publication of feminist biology research than for sex difference research. Model 1, the "maximal model" with fixed and random effects for subfield, time, feminist biology, sex difference, and gender medicine, as well as covariances among them, shows a significant, positive effect of publications that use the feminist biology paradigm on the future proportion of women among a subfield's doctoral recipients. The main effect is large: a one percentage point increase in the amount of feminist biology published during a five-year period corresponds to a 30 percentage point increase in the amount of women graduates! This effect should be interpreted in context: feminist biology comprises under $1 \%$ of publications in all but eight field-years. A one standard deviation increase in the prevalence of feminist biology corresponds to a more moderate 4.7 point increase in women's share of $\mathrm{PhDs}$ earned. 
Lockhart | 26

\begin{tabular}{|c|c|c|c|c|c|c|c|c|c|c|c|}
\hline N Obs. $=1,956$ & & del 1 & & & lodel & & & lodel & & & lodel 4 \\
\hline N Subfields $=53$ & Coef. & Std.Err. & & Coef. & Std. & & Coef. & Std. & & Coef. & Std.Err. \\
\hline feminist biology & 30.22 & $10.53 *$ & & 7.77 & & $* * *$ & 3.18 & & & 7.34 & $1.50 * * *$ \\
\hline sex difference & 0.88 & 2.49 & & 1.53 & & & -0.01 & & & -4.79 & $2.04 *$ \\
\hline gender medicine & -10.07 & 7.83 & & -1.14 & & & 2.22 & & & -0.34 & 1.46 \\
\hline fb variance & 581.16 & 63.20 & - & - & - & - & - & - & - & - & - \\
\hline sd variance & 48.67 & 6.18 & - & - & - & - & - & - & - & - & - \\
\hline gm variance & 1776.97 & 137.46 & - & - & - & - & - & - & - & - & - \\
\hline psychology & - & - & - & - & - & - & - & - & - & 9.58 & $3.88 *$ \\
\hline psychology x sd & - & - & - & - & - & - & - & - & - & 7.44 & $2.29 * * *$ \\
\hline
\end{tabular}

Table 1: The effect of research paradigms on the percent of women earning PhDs in the life sciences.

The main effects for sex difference and gender medicine are not significantly different from zero in the maximal model. The random effects for all three paradigms are large, indicating considerable variance in their effects across subfields. As Bates et al. explain, "if the effect of A ... differs reliably between subjects [or fields], uncertainty about A may be so substantial that the main effect of A is no longer significant in a model allowing for random slopes for A" (2018). Model 2 fits a more parsimonious subset of the parameters: it still allows for random slopes and intercepts by subfield and time, but it does not include random effects or covariances for the three paradigms. As such, it assumes consistent effects for each paradigm across subfields. Under that assumption, there is still a significant positive relationship between the publication of openly feminist research and the future proportion of women graduates. The effect appears smaller in this model (7.77 points more women per 1 point additional feminist publications, or 1.21 per standard deviation), indicating that outlier fields which are allowed to vary in Model 1 are pulling the average effect down in Model 2 where the effect is constrained to be the same across fields. A likelihood ratio test and theory both indicate that Model 1 is a better fit of the data (Barr et al. 2013). 
Paradigms of Sex Research and Women in STEM | 27

Model 3 uses two-way fixed effects (i.e. dummy variables for both subfield and year) to further isolate the effect of the paradigms on women's graduation rates net of trends in time and between-field differences, providing a conservative estimate. It shows a significant but smaller positive relationship between feminist publications and women's subsequent graduation rates, as well as a small but significant positive relationship for the gender medicine paradigm. Again it shows no effect for the sex difference paradigm.

I cross validated Models 1 and 2 in order to test their robustness to the selection of fields and subfields by fitting the same model to subsets of the data with each field or subfield removed. This revealed highly consistent effect sizes (not shown) for all three paradigms no matter which subfield was removed in both Models 1 and 2. As expected Model 1's maximal specification did not always converge and encountered matrix algebra errors in some of the folds, making the more parsimonious specification of Model 2 more reliable (Bates et al. 2018). However, field level cross validation did reveal interesting variation indicating that sex research paradigms have different effects in psychology subfields than they do in others. Specifically, the effect of sex difference publications in a model without psychology subfields is significant and negative, while it is significant and positive in a model that includes only psychology subfields. This is an indication that there is an interaction between psychology and the effect of sex difference research.

Model 4 tests that interaction by adding fixed effects for a dummy variable psychology and the interaction between that and sex difference research. In this model, the main effect of sex difference research, indicating its effect in life sciences outside of psychology, is significant and negative. While the coefficient for sex difference publications is smaller in absolute terms than 
Lockhart | 28

the one for feminist biology publications (-4.79 for difference compared to 7.34 for feminism), it is larger in practical terms because sex difference publications are much more prevalent and have wider variance than feminist ones. A one standard deviation increase in the amount of difference publications in a field corresponds with a 2.00 point decrease in the future proportion of women graduates. A one standard deviation increase of feminist publications in Model 4 corresponds with a 1.15 point increase in women's representation.

The interaction between psychology and sex difference is large and significant, indicating that sex difference research has an unexpectedly positive effect on women's graduation rates in psychology subfields. The effect is small: -4.79 (main) +7.44 (interaction) $=2.65$ points more women graduates per point difference publications, or 1.11 per standard deviation. Log likelihood ratio tests indicate that Model 1 (maximal specification) fits better than Model 4 (interaction with psychology), which fits better than Model 2 (fixed, non interacted paradigm effects). Although the maximal model fits best, the additional specifications provide insight into the robustness of its results and into the dynamics of between-field variation.

\section{DISCUSSION AND CONCLUSIONS}

Using newly tabulated data from the National Science Foundation on the gender of $\mathrm{PhD}$ graduates in detailed research subfields since 1970 and a full copy of the Web of Science database, I showed that the content of sex research publications is related to the future gender ratio of life science PhDs. The publication of explicitly feminist research is associated with greater proportions of women earning PhDs in life science subfields in later years. The effects of research paradigms on $\mathrm{PhD}$ gender ratios can be context-dependent. In biological and health sciences, the prevalence of the sex difference paradigm has a negative relationship with the 
Paradigms of Sex Research and Women in STEM | 29 proportion of women subsequently earning $\mathrm{PhDs}$. That effect is surprisingly reversed in psychology subfields.

I argued that scientific publications influence the gender ratio of $\mathrm{PhDs}$ by influencing and reflecting professional cultures. While the data in this paper cannot reveal specific causal mechanisms for that process, I review a wide range of literature that theorizes and tests such mechanisms. Lab experiments show that research can reinforce prejudice and stereotype threat through neurogenic essentialism, pushing girls out of STEM, while feminist approaches can buffer those effects (Moè 2012). I show the same time-ordered associations exist across the life sciences over a 5 decade span, suggesting that publications about sex influence the schemas of gender inequality in a field's professional culture. This is not surprising. Scientists generally believe their own field's research. Numerous sources point out the detrimental personal effects of research questioning the fundamental nature and merit of social groups on scientists from those groups. Such work makes it difficult to form the concordant professional identities that are key to success in graduate school (Costello 2005). Prior work has also shown that gender influences students' interest in research topics, which in turn influences selection into fields. The popularity of those topics within fields determines resource access and success in life science graduate programs. Further, my findings are generally consistent with paradigm practitioners' own agendas to either increase (feminist biology) or resist (sex difference) women's representation in science (Hubbard 1990).

My results highlight important, often neglected dimensions of other research on women in STEM. Studies of ideal worker norms and field-specific ability beliefs have focused on one half of the story: variation in the expectations of a good worker. They take for granted the (well 
Lockhart | 30

documented) negative cultural association between "woman" and "genius," "objective," or “dedicated worker." But I demonstrate that such associations are not uniform across time or scientific fields. Because beliefs about women's nature vary from the professional culture of one field to another and one year to the next, future work on gendered occupational segregation would benefit from including explicit measures of gender beliefs alongside measures of work expectations. Such measures can be constructed for other academic fields or even occupations where practitioners do not regularly publish by using different data.

More generally, my finding that there is an association between the content of published research on sex and the future sex ratio of $\mathrm{PhD}$ graduates, which is robust across a wide range of life sciences and a long time span, drives home a well established but under-appreciated claim of feminist science studies. The content of science and scientists themselves are not separable as independent, objective entities. This point is all to often reduced to the claim that scientists' social positions influence their work and its reception. This is true. But it leaves key aspects of gender and science epistemology unexamined (Brickhouse 2001). I reverse the question to remind us that the way scientists talk about sex matters, too (Hubbard 1990; Martin 1991). As numerous scholars in feminist and queer methods have noted from their own experience, we are profoundly shaped and affected by the content of our research (Compton, Meadow, and Schilt 2018).

Although the relationship between research content and $\mathrm{PhD}$ gender is modest, efforts to understand women's under-representation in science are incomplete without consideration of the content of science itself. Publishing feminist research may be one way to increase women's representation. Yet not all approaches to feminist research seem to be equal. The critical feminist 
Paradigms of Sex Research and Women in STEM | 31

biology paradigm, which aims to complicate binaries and emphasize ongoing processes of becoming sexed and gendered has a positive effect on women entering scientific fields. The same does not appear to be true for gender medicine, which embraces notions of innate sex difference, albeit in the name of women's health. Perhaps gender medicine is ineffective because it breaks theoretically and politically with earlier feminist and women's health movements (for a critique to this effect, see Epstein 2007).

More than simply printing critical feminist research, we would do well to learn from the processes by which it relates to professional culture. Feminist biology, unlike gender medicine, is not a "just add women" recipe. It involves fundamentally rethinking received wisdom about the nature of men and women, questioning in our research and our lives how things come to be sexed and gendered and what ways that matters. It means thinking in ways that give life to, rather than pathologizing, intersex, trans, nonbinary, and queer people. It means letting go of homogenous notions of a "universal woman," whose character exists without race, class, nation, religion, history, let alone individuality. It means valuing, rewarding, and funding scientists who bring such perspectives to their departments and research. And it means championing those perspectives to junior scholars as exemplars of how professional scientists think. These are transformations of research agendas, yes. But they are also transformations of mind and culture.

My findings suggest several areas for additional study. The unexpected positive relationship between sex difference research and women's graduation in psychology raises important questions: does something about psychology training inoculate students against harmful stereotypes in a way other fields could learn from? Does research on sex differences carry a different focus or tone in psychology that makes it less hostile to women? Does 
psychology have more trans-exclusive radical feminists who see the paradigm as supporting their interests? My data are limited to sex research in the life sciences, but many other fields have feminist paradigms competing with more dominant approaches. In chemistry and physics scholars have made a compelling case that their fields can be fundamentally rethought as "liberatory science" using feminist theory; that teaching it this way would diversify the range of students in the field; and that feminist theory can even meaningfully inform core substance of physics and chemistry research (e.g. Barad 1995; Barton 1997; Prescod-Weinstein 2020). Further, there has long been fierce competition between paradigms in research on other human social categories—such as race, ability, and sexuality—in the life sciences (Waidzunas 2015; Epstein 2007; Panofsky 2014). Future work should construct measures of the competing paradigms in these domains and, where possible, connect it with demographic data in order to evaluate the generalizability of my findings to other domains.

\section{ACKNOWLEDGMENTS}

I thank Will Beischel, Chalem Bolton, Elizabeth Bruch, Erin Cech, Anne Clarke, Elly Field, Christin Munsch, Kouji Takahashi, Mike Thompson-Brusstar, participants at the University of Michigan Gender and Sexuality and Medical Sociology workshops, as well as the reviewers and editors at Gender \& Society for their feedback on this project. I thank the UM Library for procuring the Web of Science data, UM's Advanced Research Computing division for providing IT resources essential to this project, and the team of NSF and RTI staff who created the custom tabulation of data from the Survey of Earned Doctorates. I was funded in part by an NICHD training grant to the Population Studies Center at the University of Michigan (T32HD007339). 
Paradigms of Sex Research and Women in STEM | 33

\section{REFERENCES}

Abbott, Andrew. 1988. The System of Professions. Chicago: University of Chicago Press.

Bailey, Kimberlyn A., David Horacek, Steven Worthington, Ampalavanar Nanthakumar, Scott Preston, and Carolina C. Ilie. 2019. "STEM/Non-STEM Divide Structures Undergraduate Beliefs About Gender and Talent in Academia." Frontiers in Sociology 4.

Barad, K. 1995. "A Feminist Approach to Teaching Quantum Physics.” In Teaching the Majority, edited by Rosser, Sue V, 43-75. Teachers College Press New York.

Barr, Dale J., Roger Levy, Christoph Scheepers, and Harry J. Tily. 2013. "Random Effects Structure for Confirmatory Hypothesis Testing." Journal of Memory and Language 68 (3): 255-78.

Barton, Angela Calabrese. 1997. "Liberatory Science Education." Curriculum Inquiry 27 (2). Routledge: 141-63.

Bates, Douglas, Reinhold Kliegl, Shravan Vasishth, and Harald Baayen. 2018. "Parsimonious Mixed Models." ArXiv:1506.04967 [Stat], May.

Belavy, Daniel L., Patrick J. Owen, and Patricia M. Livingston. 2020. "Do Successful PhD Outcomes Reflect the Research Environment Rather than Academic Ability?" PLOS ONE 15 (8).

Bluhm, Robyn. 2021. "Neurosexism and Our Understanding of Sex Differences in the Brain.” In Handbook to Feminist Philosophy of Science, edited by Kristen Intemann and Sharon Crasnow. New York: Routledge.

Brescoll, Victoria, and Marianne LaFrance. 2004. "The Correlates and Consequences of Newspaper Reports of Research on Sex Differences.” Psychological Science 15 (8): 51520.

Brickhouse, Nancy W. 2001. "Embodying Science." Journal of Research in Science Teaching 38 (3): 282-95.

Buffington, Catherine, Benjamin Cerf, Christina Jones, and Bruce A. Weinberg. 2016. "STEM Training and Early Career Outcomes of Female and Male Graduate Students." American Economic Review 106 (5): 333-38.

Cech, Erin A. 2013a. “The (Mis)Framing of Social Justice.” In Engineering Education for Social Justice, edited by Juan Lucena, 10:67-84. Philosophy of Engineering and Technology. Dordrecht: Springer Netherlands.

—. 2013b. "Ideological Wage Inequalities?" Social Forces 91 (4). Oxford Academic: 114782.

— 2014. "Culture of Disengagement in Engineering Education?" Science, Technology, \& Human Values 39 (1). SAGE Publications Inc: 42-72.

—. 2017. "Rugged Meritocratists." Socius 3 (January): 2378023117712395.

Cech, Erin A., and Mary Blair-Loy. 2019. "The Changing Career Trajectories of New Parents in STEM.” Proceedings of the National Academy of Sciences 116 (10): 4182-87. 
Cech, Erin A., Mary Blair-Loy, and Laura E. Rogers. 2018. "Recognizing Chilliness." American Journal of Cultural Sociology 6 (1): 125-60.

Ching, Boby Ho-Hong, and Jason Teng Xu. 2018. "The Effects of Gender Neuroessentialism on Transprejudice.” Sex Roles 78 (3): 228-41.

Coleman, Jill M., and Ying-Yi Hong. 2008. "Beyond Nature and Nurture." Self and Identity 7 (1): 34-53.

Compton, D'Lane, Tey Meadow, and Kristen Schilt, eds. 2018. Other, Please Specify. Oakland: University of California Press.

Costello, Carrie Yang. 2005. Professional Identity Crisis. Nashville: Vanderbilt University Press. Davis, Georgiann. 2015. Contesting Intersex. New York: NYU Press.

Donovan, Brian M., Molly A. M. Stuhlsatz, Daniel C. Edelson, and Zoë E. Buck Bracey. 2019. “Gendered Genetics." Science Education 103 (4): 719-49.

Epstein, Steven. 2007. Inclusion. Chicago: University of Chicago Press.

Fausto-Sterling, Anne. 1992. "Building Two-Way Streets." NWSA Journal 4 (3): 336-49. - 2005. "The Bare Bones of Sex." Signs 30 (2): 1491-1527.

Fine, Cordelia. 2013. "Is There Neurosexism in Functional Neuroimaging Investigations of Sex Differences?" Neuroethics 6 (2): 369-409.

Forbes, TehQuin D. 2020. “Queer-Free Majors?” Journal of LGBT Youth, September. Routledge. Haraway, Donna Jeanne. 1988. "Situated Knowledges." Feminist Studies 14 (3): 575-99.

Herschberger, Ruth. 1948. Adam's Rib. New York: Pellegrini \& Cudahy.

Hilton, Emma, and Jenny Whyte. 2020. "Project Nettie." Project Nettie. https://projectnettie.wordpress.com/. Accessed January 8.

Hochschild, Arlie Russell, and Anne Machung. 1989. The Second Shift. New York: Viking. Hubbard, Ruth. 1990. The Politics of Women's Biology. New Brunswick: Rutgers University Press.

Hubbard, Ruth, Sandra Harding, Nancy Tuana, Sue V. Rosser, and Anne Fausto-Sterling. 1993. "Comments on Anne Fausto-Sterling's 'Building Two-Way Streets' [with Response]." NWSA Journal 5 (1): 45-81.

Hyde, Janet Shibley. 2005. "The Gender Similarities Hypothesis.” American Psychologist 60 (6): $581-92$.

Johnson, Matthew. 2020. Undermining Racial Justice. Histories of American Education. Ithaca [New York]: Cornell University Press.

Karkazis, Katrina, and Rebecca M Jordan-Young. 2015. "Debating a Testosterone 'Sex Gap.'” Science 348 (6237): 858-60.

Lamont, Michèle. 2009. How Professors Think. Cambridge: Harvard University Press.

Laurence, David. 2014. "Opportunity Costs of the PhD." The Trend. Modern Language Association. 
Paradigms of Sex Research and Women in STEM | 35

Leslie, Sarah-Jane, Andrei Cimpian, Meredith Meyer, and Edward Freeland. 2015. "Expectations of Brilliance Underlie Gender Distributions across Academic Disciplines." Science 347 (6219): 262-65.

Lockhart, Jeffrey W. 2020. "Historical Authority in the Science of Sex." In Far Right Revisionism and the End of History: Alt/Histories, edited by Louie Dean Valencia-García, 359-86. New York: Routledge.

Lowie, Robert H., and Leta Stetter Hollingworth. 1916. "Science and Feminism." The Scientific Monthly 3 (3): 277-84.

Martin, Emily. 1991. "The Egg and the Sperm.” Signs 16 (3): 485-485.

McCabe, Janice. 2005. "What's in a Label?" Gender \& Society 19 (4): 480-505.

Meadow, Tey. 2013. “Queer Numbers.” In American Sociological Association. New York.

Messer-Davidow, Ellen. 2002. Disciplining Feminism. Durham: Duke University Press.

Moè, Angelica. 2012. “Gender Difference Does Not Mean Genetic Difference." Learning and Individual Differences 22 (1): 20-24.

Musto, Michela. 2019. "Brilliant or Bad.” American Sociological Review 84 (3): 369-93.

Panofsky, Aaron. 2014. Misbehaving Science. Chicago: The University of Chicago Press.

Pfeffer, Carla A. 2018. “Queer Accounting.” In Other: Please Specify, 304-25. Oakland: Univ of California Press.

Philosopher, T. 2019. "I Am Leaving Academic Philosophy Because of Its Transphobia Problem.” Medium. May 30. https://medium.com/@transphilosopher33/i-am-leavingacademic-philosophy-because-of-its-transphobia-problem-bc618aa55712.

Pielke, Roger, and Madeleine Pape. 2019. "Science, Sport, Sex, and the Case of Caster Semenya." Issues in Science and Technology XXXVI (1): 56-63.

Pleasants, Robert K. 2011. "Men Learning Feminism." Men and Masculinities 14 (2). SAGE Publications Inc: $230-50$.

Poulain de La Barre, François. 1677. The Woman as Good as the Man, or, The Equallity of Both Sexes. Translated by A.L. Cornhill: T.M. for N. Brooks.

Prescod-Weinstein, Chanda. 2020. "Making Black Women Scientists under White Empiricism." Signs: Journal of Women in Culture and Society 45 (2): 421-47.

Quadagno, Jill S. 1979. "Paradigms in Evolutionary Theory." American Sociological Review 44 (1): 100-109.

Richardson, Sarah S., Meredith Reiches, Heather Shattuck-Heidorn, Michelle Lynne LaBonte, and Theresa Consoli. 2015. "Opinion." Proceedings of the National Academy of Sciences 112 (44): 13419-20.

Richardson, Sarah S, Meredith W Reiches, Joe Bruch, Marion Boulicault, Nicole E Noll, and Heather Shattuck-Heidorn. 2020. "Is There a Gender-Equality Paradox in Science, Technology, Engineering, and Math (STEM)?” Psychological Science, 4.

Ridgeway, Cecilia L. 2011. Framed by Gender. Oxford: Oxford University Press. 
Risman, Barbara J. 2001. "Calling the Bluff of Value-Free Science.” American Sociological Review 66 (4): 605-11.

Roy, Deboleena. 2012. "Cosmopolitics and the Brain.” In Neurofeminism, edited by Robyn Bluhm, Anne Jaap Jacobson, and Heidi Lene Maibom, 175-92. London: Palgrave Macmillan UK.

Sanz, Veronica. 2017. "No Way Out of the Binary." Signs 43 (1): 1-27.

Schilt, Kristen. 2010. Just One of the Guys? University of Chicago Press.

Seron, Carroll, Susan Silbey, Erin Cech, and Brian Rubineau. 2018. "“I Am Not a Feminist, But. .." Work and Occupations 45 (2): 131-67.

Storage, Daniel, Zachary Horne, Andrei Cimpian, and Sarah-Jane Leslie. 2016. "The Frequency of 'Brilliant' and 'Genius' in Teaching Evaluations Predicts the Representation of Women and African Americans across Fields." PLOS ONE 11 (3): e0150194.

Subramaniam, Banu. 2000. "Snow Brown and the Seven Detergents." Women's Studies Quarterly 28 (1/2): 296-304.

Summers, Lawrence H. 2005. "Remarks at NBER Conference on Diversifying the Science \& Engineering Workforce." Harvard Office of the President. February 18. https://web.archive.org/web/20050301023424/http://www.president.harvard.edu/ speeches/2005/nber.html.

Taylor, Catherine J. 2016. “"Relational by Nature'?” American Journal of Sociology 122 (1): 4989.

Tuana, Nancy. 1983. "Re-Fusing Nature/Nurture.” Women's Studies International Forum 6 (6): 621-32.

Waidzunas, Tom. 2015. The Straight Line. Minneapolis: University of Minnesota Press.

World Rugby. Press Release. 2020. "Landmark World Rugby Transgender Workshop Important Step towards Appropriate Rugby-Specific Policy," February 27. 